\title{
Avaliação das condições higiênico-sanitárias na comercialização de frutas e hortaliças no município de Manhuaçu, Minas Gerais
}

\section{Evaluation of the hygienic-sanitary conditions in the commercialization of fruits and vegetables in the city of Manhuaçu, Minas Gerais}

\author{
Dilson Fagundes Ribeiro ${ }^{1}$, Rosane da Silva Rodrigues ${ }^{2}$
}

\begin{abstract}
Resumo: Em feiras livres e supermercados uma ampla variedade de produtos alimentícios processados e in natura são comercializados, entre eles destacam-se frutas e hortaliças. Esses locais têm sido objeto de estudo devido as frequentes más condições higiênico-sanitárias das bancadas, dos utensílios, dos equipamentos e dos manipuladores. O objetivo deste trabalho foi avaliar as condições higiênico-sanitárias da comercialização de frutas e hortaliças em feira livre e supermercados no município de Manhuaçu (MG), tendo como base as recomendações da RDC MS/Anvisa n 216 de 2004 e a RDC MS/Anvisa $\mathrm{n}^{\circ} 275$ de 2002. Foi elaborado um questionário estruturado com questões abertas para entrevista com os manipuladores e questões fechadas (checklist) para observações de condições pontuais de higiene nos locais de venda. Foi verificado que tanto na feira livre como nos supermercados haviam diversas inadequações relacionadas às condições higiênico-sanitárias. Portanto, pode-se concluir que nenhum dos estabelecimentos atende a todos os itens avaliados, ressaltando-se a importância para o cumprimento das legislações que visam assegurar a disponibilização de alimentos seguros ao consumidor.
\end{abstract}

Palavras-chave: Feira livre; Supermercados; Higiene; Vegetais

Abstract: On street markets and supermarkets a wide diversity of processed food products and "in natura" are marketed, among them stand out fruits and vegetables. These locations have been studied due to poor sanitary conditions of countertops, utensils, equipment and handlers. The objective of this study was to assess the sanitary conditions of marketing of fruits and vegetables in the city of Manhuaçu (MG), based on the recommendations of the RDC MS / ANVISA N ${ }^{\circ} .216$ of 2004 and RDC N $\mathrm{N}^{\circ} 275$ 2002. It has made an organized questionnaire containing open questions for interview and closed questions (checklist) to be observed about the hygiene conditions of the street markets and the supermarket. It was checked that both the street market and supermarkets had several inadequacies concerning the sanitary conditions. Therefore, it can be concluded that no establishments cater to all items, emphasizing the importance for the fulfillment of laws aimed at ensuring the provision of safe food to consumers of safe food to consumers.

Key words: Fair free, Supermarket; Hygiene; Vegetables.

\footnotetext{
*Autor para correspondência

Recebido para publicação em 04/05/2016; aprovado em 12/01/2017

${ }^{1}$ Economista Doméstico, Especialista em Ciência dos Alimentos, Mestre em Ciência e Tecnologia de Alimentos. Universidade Federal de Pelotas, Pelotas-RS. E-mail: dilsonfagundes@hotmail.com

${ }^{2}$ Engenheira Agrônoma, Doutora em Tecnologia de Alimentos, Professora Associada, Centro de Ciências Químicas, Farmacêuticas e de Alimentos, Universidade Federal de Pelotas, Pelotas-RS. E-mail: fragatao@gmail.com
} 


\section{INTRODUÇÃO}

As frutas e hortaliças são comercializadas ao consumidor final via pequeno varejo (feiras livres, sacolões, mercearias e mercadinhos) e via grandes redes de supermercados (ARAÚJO et al., 2011).

Dentre estes, a feira livre pode ser considerada um dos locais mais tradicionais em que se comercializam alimentos a varejo, sendo frequentada, em sua maior parte, por parcela da população que já possui o hábito de ir à feira (GOMES et al., 2012).

Derivada do latim feria, a palavra feira designa locais de realização de comércio ou mercado livre em épocas ou dias fixos, onde são expostas e vendidas mercadorias e onde há reunião de produtores e consumidores para comercialização de produtos característicos, predominantemente da região (SILVA et al., 2012). Além disso, as feiras e mercados públicos podem ser considerado patrimônio culturais de uma cidade, pois oferecem diversos produtos e serviços em um único local, revelam hábitos e manifestações culturais, sendo de grande importância sócio-econômico-cultural para o município (OLIVEIRA et al., 2008).

Por parte dos consumidores, há uma preferência na aquisição de alimentos vendidos em feiras livres, por considerarem estes alimentos frescos e de qualidade superior (SANTOS et al., 2013). Porém, estes produtos muitas vezes são comercializados em condições que propiciam a contaminação por microrganismos quando não são adotadas práticas adequadas de manipulação e exposição dos alimentos para a venda (SANTOS et al., 2013).

A comercialização de produtos alimentícios na maioria das feiras livres é considerada de higiene insatisfatória, constituindo-se em um importante vetor no processo de contaminação e proliferação de enfermidades de origem alimentar (ALMEIDA et al., 2011).

Os supermercados, por sua vez, desempenham um importante papel na distribuição e comercialização de alimentos e uma das iniciativas desse setor para reduzir custos é implantar centrais de manipulação e acondicionamento de produtos perecíveis (OLIVEIRA et al., 2008). São mais exigentes do que aquelas quanto à padronização, classificação e qualidade do produto (ARAÚJO et al., 2011).

Os supermercados possuem grande importância no cotidiano das pessoas, geram emprego e disponibilizam para a sociedade os mais variados produtos, representando o último elo da cadeia entre um produto e seus consumidores finais. Como muitos dos produtos comercializados são alimentos, é indispensável a adoção de boas práticas para garantir a segurança e qualidade do alimento. Os supermercados podem ser classificados de acordo com o formato da loja em: loja de conveniência, loja de sortimento limitado, supermercado compacto, supermercado convencional, superloja, hipermercado, loja de depósito e clube atacadista. Essa classificação é de acordo com a área de vendas $\left(\mathrm{m}^{2}\right)$, número de itens, percentual de vendas de não alimentos e número de seções (RIOS, 2012).

Entre os principais fatores que podem ocasionar alterações na qualidade dos alimentos in natura estão: estrutura e espaço inadequados, ausência de equipamentos de conservação, falta de água encanada, conservação e higiene inadequada dos alimentos e dos utensílios, más condições de higiene por parte dos manipuladores e presença de animais
(BEIRÓ; SILVA, 2009). Destes, a falta de preparo por parte dos manipuladores de alimentos é considerada uma das principais causas de enfermidades de origem alimentar, relacionando-se diretamente com a contaminação dos alimentos, decorrente de doenças, de maus hábitos de higiene e práticas inadequadas (CAVALLI; SALAY, 2007). Segundo Almeida et al. (2011) e Beiró e Silva (2009), as enfermidades de origem alimentar são consideradas o maior problema de saúde pública em todo o mundo, sendo os manipuladores um dos principais veículos de contaminação.

$\mathrm{O}$ atendimento às Boas Práticas (BP), as condições higiênicas do ambiente em que se comercializam alimentos e o cumprimento das exigências oficiais e legais, são requisitos importantes para a segurança e qualidade dos alimentos (LUNDGREN et al., 2009). Soma-se a isso o fato de que os alimentos devem satisfazer os critérios de qualidade estipulados pelos consumidores (RODRIGUES, 2004).

Embora a comercialização de frutas e hortaliças em feiras seja importante para economia e para a sociedade, não existe uma legislação específica para regulamentar a atividade. Os princípios seguidos se baseiam na RDC MS $n^{\circ} 216$ e na RDC MS n ${ }^{\circ} 275$ as quais não são específicas para estes estabelecimentos. Assim, o objetivo deste trabalho foi avaliar as condições higiênico-sanitárias dos estabelecimentos que comercializam frutas e hortaliças in natura em feira livre e supermercados no município de Manhuaçu - MG, Brasil.

\section{MATERIAL E MÉTODOS}

A pesquisa foi realizada nos meses de junho e julho de 2014 no município de Manhuaçu, Minas Gerais, Brasil, em feira livre que ocorre no período da manhã das quartas-feiras e sábados, localizada em uma área específica de um bairro central da cidade, e em 15 supermercados localizados no centro e em bairros periféricos da cidade, tendo como foco de observação os setores onde são comercializadas frutas e hortaliças in natura.

A feira livre avaliada possui um total de 137 barracas que comercializam os mais diversos tipos de produtos, tendo participado deste estudo 42 feirantes que comercializavam frutas e hortaliças in natura. Nos supermercados foram entrevistados 1 manipulador de frutas e hortaliças por estabelecimento, totalizando 15 entrevistas. Foi elaborado um questionário estruturado que continha questões abertas para entrevista e questões fechadas (checklist) para serem observadas. Aplicado na forma de entrevista individual, versou sobre o conhecimento das boas práticas de manipulação de alimentos e das formas de higienização de frutas e hortaliças, bem como dos utensílios, equipamentos e bancadas. Paralelamente foi utilizado um roteiro de inspeção (checklist) adaptado de Xavier et al. (2009) e baseado em recomendações da RDC n ${ }^{\circ}$. 216/04 da Agência de Vigilância Sanitária (BRASIL, 2004), contendo 41 questões a serem observadas sobre as condições higiênico-sanitárias na comercialização de frutas e hortaliças na feira e nos supermercados.

As observações do checklist foram divididas em cinco grupos. O grupo 1 tratava das observações acerca das instalações, higiene da área e presença de animais e/ou insetos; o grupo 2 versou sobre hábitos de higiene e vestimenta dos manipuladores; o grupo 3 sobre o abastecimento e a qualidade da água; o grupo 4 com questões 
acerca das condições higiênicas dos alimentos, das embalagens e do armazenamento; e o grupo 5 sobre a higiene e conservação dos utensílios utilizados para o manuseio das frutas e hortaliças.

As entrevistas foram realizadas no próprio local de trabalho e foi assegurado que a identidade dos entrevistados, número da barraca e/ou nome do estabelecimento não seriam revelados na divulgação do trabalho.

\section{RESULTADOS E DISCUSSÃO}

Verificou-se que $100 \%$ dos manipuladores de frutas e hortaliças de feiras e supermercados já ouviram falar em boas práticas de manipulação de alimentos e todos manifestaram interesse em receber treinamento sobre as mesmas. Porém, apenas 30\% dos feirantes seguem algum manual de boas práticas. Em contrapartida, $60 \%$ dos atendentes de supermercados seguem manuais para realização da higiene das frutas e hortaliças, bem como dos utensílios, equipamentos e bancadas. Tal resultado corrobora com o argumento de Araújo et al. (2011) de que supermercados, em sua maioria, são mais exigentes quanto à padronização e qualidade dos produtos oferecidos à venda.

Com base nos resultados referentes às fontes de contaminação é possível perceber que embora exista por parte dos feirantes e atendentes de supermercados o interesse em receber treinamento sobre boas práticas de manipulação, muitos acreditam que a principal fonte de contaminação dos alimentos sejam os agrotóxicos, seguido de microrganismos, metais pesados e falta de higiene por parte dos manipuladores. Considerando que a falta de higiene por parte dos manipuladores é uma das principais causas de enfermidades de origem alimentar (ALMEIDA et al., 2011), evidencia-se a necessidade de treinamento e qualificação de manipuladores de frutas e hortaliças para que se comercialize alimentos dentro dos padrões de segurança e qualidade.

Quanto à forma de higienização, 50\% dos feirantes utilizam água com detergente para limpeza das barracas, não obedecendo as concentrações recomendadas pelo fabricante. Os demais $50 \%$ dos feirantes entrevistados alegaram fazer a limpeza utilizando soluções cloradas, respeitando o tempo e a concentração recomendada nos rótulos. Nos supermercados, $66 \%$ alegaram utilizar solução clorada em diluição e tempo de contato recomendado pelo fabricante, conforme a recomendação da RDC $n^{\circ} 216$; o restante utiliza apenas água e detergente para a limpeza.

$\mathrm{Na}$ feira livre foi verificado que na área externa das barracas havia sujidades provenientes de resíduos dos vegetais comercializados, presença de animais circulando livremente e piso de cimento grosso, considerado material de difícil higienização.

Os resultados observados nos supermercados e na feira livre sobre as condições das instalações são apresentados na Tabela 1, onde é possível observar o percentual de conformidade com as recomendações da RDC MS $n^{\circ}$ 216/2004 (BRASIL, 2004).

Rodrigues (2004) avaliou as condições higiênicosanitárias da comercialização de frutas e hortaliças em Brasília e constatou que $90 \%$ dos estabelecimentos apresentam-se em condições insatisfatórias, percentual acima do observado neste estudo. Segundo o autor, os maiores índices de inadequações referem-se às condições físicas de produção e transporte, aos manipuladores, higiene pessoal e edificações e instalações.

Tabela 1. Grau de conformidade (\%) com a RDC MS n 216/2004 das condições das instalações, higiene da área e presença de animais e/ou insetos em supermercados e feira livre de Manhuaçu, MG

\begin{tabular}{lcc}
\hline \multicolumn{1}{c}{ Critério observado* } & Supermercados & Feira livre \\
\hline Área livre de animais e acúmulo de lixo & 93,3 & $90,5^{*}$ \\
Piso de material de fácil higienização & 66,7 & 0 \\
Piso em adequado estado de higienização & 66,7 & 47,6 \\
Bancadas em adequado estado de conservação & 73,3 & 28,6 \\
Bancadas laváveis e isentas de rugosidade & 73,3 & 19 \\
Lixeiras com acionamento de pedal & 53,3 & 47,6 \\
\hline
\end{tabular}

*Dentro das barracas, em sua maior parte, não havia presença de animais, porém na feira eram comercializadas aves e por ser uma área com portão aberto foi possível observar também a presença de cães transitando livremente pelo local.

Na Tabela 2 são apresentados os resultados observados sobre os hábitos higiênicos e vestimentas dos manipuladores de frutas e hortaliças. Pode-se observar que na feira livre e nos supermercados há problemas relacionados ao asseio pessoal e à manipulação de dinheiro e alimentos pelo mesmo atendente. Os problemas podem levar à contaminação dos alimentos e provocar a disseminação de doenças.

Beiró e Silva (2009) avaliaram as condições higiênicosanitárias de alimentos comercializados em feiras livres no Distrito Federal e verificaram que $52,1 \%$ dos feirantes não utilizavam touca no cabelo e 69,6\% utilizavam adornos.

Em relação aos supermercados é possível observar que um pequeno percentual não atende às exigências para instalações e hábitos de higiene dos funcionários que manipulam as frutas e hortaliças, o que constitui um fator negativo que poderá ser julgado pelos clientes. De acordo com Rios (2012), as exigências dos clientes por altos padrões de qualidade dos produtos e as normas estabelecidas pela legislação sanitária induzem os supermercados a incorporarem um conjunto de ações voltadas para o controle de qualidade dos alimentos, como Boas Práticas, que visam um diferencial competitivo e de qualidade.

A ausência de uma legislação específica para feiras livres dificulta a compreensão e avaliação do que é adequado para a prática de manipulação e preparo dos alimentos nestes locais, por isso, o percentual de adequações é inferior ao índice dos supermercados.

Em relação ao quesito abastecimento de água, avaliado no grupo 3, foi observado que em $100 \%$ dos supermercados havia água encanada, em contrapartida, na feira livre apenas 4 barracas possuíam.

$\mathrm{Na}$ Tabela 3 são apresentados os resultados das observações feitas sobre a higiene dos alimentos comercializados pertencentes aos itens observados no grupo 4. 
Segundo Xavier et al. (2009), um dos problemas que pode ser encontrado nas feiras é a falta de atenção ao manipular e armazenar os alimentos que, quando irregulares, podem ser a causa de problemas como toxinfecções alimentares.

Silva et al. (2012) avaliaram as condições higiênicosanitárias da comercialização de frutas e hortaliças na feira livre do município de Luís Gomes - RN e verificaram que a feira não possuía condições básicas para o correto controle higiênico-sanitário.

Costa e Silva (2011) avaliaram a satisfação dos clientes da feira livre de Pombal, PB, e verificaram que 58\% estão insatisfeitos quanto à organização, higiene e regularidade das barracas, fatores que comprometem a qualidade do alimento.

Tabela 2. Hábitos higiênicos e condições das vestimentas dos manipuladores de frutas e hortaliças in natura em supermercados e feira livre de Manhuaçu, Minas Gerais

\begin{tabular}{lcc}
\hline Critério observado & Supermercados (\%) & Feira livre (\%) \\
\hline Asseio pessoal (mãos, unhas limpas e sem esmaltes, toucas...) & 80 & 61,9 \\
Lavam as mãos antes da manipulação & 53,3 & 0 \\
A pessoa que manipula os alimentos é diferente das que manipulam dinheiro & 80 & 9,5 \\
Uniforme na cor clara & 80 & 26,2 \\
Uniformes limpos e em bom estado de conservação & 66,6 & 19 \\
Possui banheiro & 100 & $100^{*}$ \\
Banheiro separado por sexo & 46,7 & $100^{*}$ \\
Manipuladores apresentam feridas ou sintomas de enfermidades & 6,7 & 4,8 \\
\hline
\end{tabular}

* Possui um banheiro masculino e um banheiro feminino para toda a feira.

Tabela 3. Condições de higiene, embalagem e disposição das frutas e hortaliças in natura comercializadas em supermercados e feira livre de Manhuaçu, Minas Gerais

\begin{tabular}{lcc}
\hline Critério & Supermercados (\%) & Feira livre (\%) \\
\hline Separam adequadamente cada tipo de alimento & 73,3 & 76,2 \\
Os alimentos estão protegidos da ação dos raios solares, chuvas e outros & 60 & 35,7 \\
Alimentos em perfeitas condições de higiene & 60 & 35,7 \\
Alimentos estragados em contato com alimentos de boa qualidade & 6,6 & 9,5 \\
Alimentos são embalados em sacolas plásticas brancas, transparentes & 80 & 80,9 \\
apropriadas para alimentos & & 7,1 \\
Alimentos enrolados no jornal & 13,3 & 47,6 \\
Armazenamento adequado das embalagens & 66,7 & 7 \\
\hline
\end{tabular}

Na tabela 4 são apresentados o itens avaliados no grupo 5, que versava sobre condições higiênico-sanitárias dos utensílios utilizados. Foi possível observar que a maioria dos estabelecimentos e das barracas possuíam utensílios em boas condições de higiene, porém são armazenados de forma imprópria, o que viabiliza a contaminação por microrganismos.
Segundo Beiró e Silva (2009), entre os principais fatores que podem ocasionar alterações na qualidade dos alimentos estão os utensílios utilizados. A RDC MS n ${ }^{\circ}$ 216/2004 contempla aspectos higiênicos que envolvem instalação do local, dos utensílios e dos manipuladores. Para avaliação dos utensílios devem ser observados o estado de conservação, a frequência e a forma correta de higienização (BRASIL, 2004).

Tabela 4. Condições higiênico-sanitárias dos utensílios utilizados em frutas e hortaliças in natura comercializadas em supermercados e feira livre de Manhuaçu, Minas Gerais

\begin{tabular}{lcc}
\hline Critério & Supermercados (\%) & Feira livre (\%) \\
\hline Material em adequado estado de conservação & 73,3 & 83,3 \\
De fácil higienização & 73,3 & 90,5 \\
Armazenados em local apropriado & 40 & 47,6 \\
\hline
\end{tabular}

\section{CONCLUSÕES}

A avaliação das condições higiênico-sanitárias dos estabelecimentos que comercializam frutas e hortaliças in natura no município de Manhuaçu, MG, Brasil, indica que nenhum dos estabelecimentos atendem a todos os itens avaliados, o que coloca em risco as condições dos alimentos comercializados na feira livre e nos supermercados.

\section{REFERÊNCIAS}

ALMEIDA, R. B.; DINIZ, W. J. S.; SILVA, P. T. V.; ANDRADE, L. P.; DINIZ, W. P. S.; LEAL, J. B. G.; BRANDESPIM, D. F.; Condições higiênico-sanitárias da comercialização de carnes em feiras livres de Paranatama, PE. Alimentos e Nutrição, v. 22, n. 4, p. 585-592, 2011.

ARAÚJO, H. S.; FIRETTI, R.; RÓS, A. B; NARITA, N. Os principais sistemas de comercialização de hortaliças. Pesquisa e tecnologia, v. 8, n. 2, p. 1-6, 2011.

BEIRÓ, C. F. F.; SILVA, M. C. Analise das condições de higiene na comercialização de alimentos em uma feira livre do Distrito Federal. Universitas: Ciências da Saúde, v. 7, n. 1, p. 13-28, 2009.

BRASIL, Ministério da Saúde. Secretaria de Vigilância Sanitária. Resolução RDC n. 275, de 21 de outubro de 2002. 
Aprova o regulamento Técnico sobre Procedimentos Operacionais Padronizados aplicados aos estabelecimentos produtores/industrializadores de alimentos e a lista de verificação das boas práticas de fabricação em estabelecimentos produtores/industrializadores de alimentos. Diário Oficial da União - Seção 1. Brasília, DF, 06 de novembro de 2002.

BRASIL, Ministério da Saúde. Secretaria de Vigilância Sanitária. Resolução RDC n. 216, de 15 de setembro de 2004. Aprova o Regulamento Técnico sobre Boas Práticas de Fabricação para Serviços de Alimentação. Diário Oficial da União - Seção 1. Brasília, DF, 15 de setembro de 2004.

CAVALLI, S. B.; SALAY, E. Gestão de pessoas em unidades produtoras de refeições comerciais e segurança alimentar. Revista de Nutrição, v. 20, n. 6, p. 657-667, 2007.

COSTA, C. C.; SILVA, D. S. O. Identificação dos consumidores de hortaliças da feira livre de Pombal-PB: aspectos socioeconômicos e culturais. Revista Verde de Agroecologia, v. 6, n.1, p. 56-60, 2011.

GOMES, P. M. A.; BARBOSA, J. G.; COSTA, E. R.; JÚNIOR, I. G. S. Avaliação das condições higiênicas sanitárias das carnes comercializadas na feira livre do município de Catolé do Rocha-PB. Revista Verde de Agroecologia, v. 7, n. 1, p. 225-232, 2012.

LUNDGREN, P. U.; SILVA, J. A.; MACIEL, J. F.; FERNANDES, T. M. Perfil da qualidade higiênico-sanitária da carne bovina comercializada em feiras livres e mercados públicos de João Pessoa/PB - Brasil. Alimentos e Nutrição, v. 20, n. 1, p. $113-119,2009$.

OLIVEIRA, R. B. A.; ROLIM, M. B. Q.; MOURA, A. P. B. L.; MOTA, R. A.; Avaliação higiênico-sanitária dos boxes que comercializam carnes em dois mercados públicos da cidade do Recife-PE/Brasil, Revista de Medicina Veterinária, v. 2, n. 4, p. 10-16, 2008.

RIOS, T. C. Boas Práticas em Supermercados e na Central de Armazenamento e Distribuição. 2012. 56f. Monografia (Graduação em Engenharia de Alimentos), Universidade Federal do Rio Grande do Sul, Porto Alegre, 2012.

RODRIGUES, D. M. S. Perfil-higiênico sanitário de feiraslivres do Distrito Federal e avaliação da satisfação dos seus usuários. 2004. 64f. Monografia (Especialização em Qualidade de Alimentos), Universidade de Brasília, Brasília, 2004.

SANTOS, D. B.; MACHADO, M. S.; SAMPAIO, A. H. R.; VIEIRA, L. M. Avaliação das condições higiênico-sanitárias da feira livre da colônia de pescadores do município de Uruçuí-PI. Enciclopédia Biosfera, v. 9, n. 16, p. 2433-2443, 2013.

SIlVA, A. G.; SILVA, V. A. F.; SILVA, M. L.; MACHADO, A. L. Avaliação da condição higiênico-sanitária na comercialização de frutas e hortaliças em feiras livres do município de Luís Gomes/RN - Brasil. In: VII Congresso Norte Nordeste de Pesquisa e Inovação, 2012, Palmas. Anais do VII Congresso Norte Nordeste de Pesquisa e Inovação. Palmas, 2012.

XAVIER, A. Z. P.; VIEIRA, G. D. G.; RODRIGUES, L. O. M.; VALVERDE, L. O.; PEREIRA, V. S. Condições higiênico-sanitárias das feiras-livres do município de Governador Valadares. 2009. 94f. Monografia (Curso de especialização em Nutrição) - Universidade do Vale do Rio Doce, Minas Gerais, 2009. 